\title{
Body Weight, Carapace Length and Width Relationship and Condition Factor of the Mud Crab Scylla serrata (Forskal) in Mangrove Ecosystem
}

\author{
Sarvabhowma Chakravarty MYLA ${ }^{1 *}$, Vijaya Bharathi TIRUMANI², \\ Rama Chandra Ganesh PATURI ${ }^{1}$
}

\author{
${ }^{1}$ Andhra University, Department of Marine Living Resources, College of Science and Technology, Visakhapatnam 530003, \\ India; mylaschakravarty@gmail.com (*corresponding author);ganeshmbt@gmail.com \\ ${ }^{2}$ State Institute of Fisheries Technology, Jagannaickpur, Kakinda 533 002, India; vijayabharathi_tv@yahoo.co.in
}

\begin{abstract}
The relationship of length-weight and width-weight of the carapace and the relative condition factor of mud crab Scylla serrata from Coringa Wildlife Sanctuary (Andhra Pradesh, India) was the subject of present study. Significant difference in both males and females was observed between carapace length-weight and carapace width-weight, with a linear relationship. The regression values of both genders were found to be statistically significant. The regression equations calculated for lengthweight were $W=0.00000178 \mathrm{~L}^{3.1139}(\mathrm{r}=0.95)$ for males, $\mathrm{W}=0.00000520 \mathrm{~L}^{2.8056}(\mathrm{r}=0.94)$ for females and for genders combined it was $\mathrm{W}=0.0000297 \mathrm{~L}$ 2.9891 $(r=0.94)$. In case of carapace width-weight relationship of males, females and genders combined the regression equations were $\mathrm{W}=0.00000121 \mathrm{CW}^{3.0426}(\mathrm{r}=0.92), \mathrm{W}=0.00000178 \mathrm{CW}^{2.775}(\mathrm{r}=0.93)$ and $\mathrm{W}=$ $0.00000204 \mathrm{CW}^{2.9210}(\mathrm{r}=0.92)$ respectively. The male crabs showed positive allometric growth, whereas females had negative allometric growth. Analysis of covariance confirmed remarkable difference between males and females in the growth pattern. The mean relative condition factor (Kn values) of both males and females and of the pooled genders ranged from 0.680 (April) to 1.029 (November). A gradual raise in Kn values was observed from small- to big- sized crabs in both genders. Peak values were observed in $12.0-13.9 \mathrm{~cm}$ size group in November.
\end{abstract}

Keywords: body weight, carapace length and width, Coringa mangroves, relative condition factor, Scylla serrata

\section{Introduction}

Mud crab, Scylla serrata (Forskal) is the only species of the family Portunidae inhabiting the mangroves of the tropical latitudes particularly Indo-Pacific (Hill, 1975; Overton et al., 1997) and subtropical environments of China and Japan (Sakai, 1976; Dai and Yang, 1991), having tolerance to a wide range of environmental variations. It ranks first among crabs because of its large size, high meat quality, delicate taste (Rattanachote and Dangwatanakul, 1992). The species is widely distributed in the Coringa mangroves of Gautami-Godavari (India) estuarine system and commands a very good market demand for local consumption and export.

The length-weight or width-weight relationships are important prerequisites to know the variations in weight from the known length or width indicating feeding, growth, breeding etc., and to estimate the population size of a stock for the purpose of its exploitation (Atar and Secer, 2003). According to Mohapatra (2008) the carapace width-weight relationship, condition factor and relative condition factors in mud crabs are important for biological studies like catch data, yield recruit, model analysis and so on. Individual variation in length-weight relationship has been considered as the general condition of the organism to analyze the condition factor or k-factor or prepondral index (Le Cren, 1951).

Many studies contributed on these lines on Scylla serrata and added important data to those of Lalitha Devi (1985) who studied the relationship between width and weight in crabs of Kakinada region, Andhra Pradesh. Poovachiranon (1992) has made biological studies of the mud crab $S$. serrata of mangrove ecosystem in the Andaman Sea. Length-weight relationship of $S$. serrata in the Sundarban mangroves has been studied by Ali et al. (2004). Davis (2004) has studied the relationship between carapace width and mass in mature females of $S$. serrata in the sub-tropical Umalazi estuary. Ewel (2007) has investigated mean carapace width of $S$. serrata at different locations in Kosrae. Allometric relationship between carapace width and weight in mangrove crabs (S. serrata) on Kosrae of Macronesia has been reported by Bonine et al. (2008). Studies on carapace width and weight relationships, relative condition factor of mud crabs $S$. serrata and $S$. tranquebarica have been made by Mohapatra et al. (2010) in Chilka lagoon. 
Thirunavukkarasu and Shanmugam (2011) have estimated the carapace length-weight and carapace widthweight relationships of the mud crab $S$. tranquebarica. Laura et al. (2016) have studied the size-distribution, growth pattern and condition factor of mangrove crab $S$. serrata in the coastal waters of Western Seram, Indonesia. Wahio et al. (2016) have assessed the size distribution, length-weight realationship and size at the onset of sexual maturity of the orange mud crab (S. olivacea) from Malaysian waters.

The present study aimed to assess the relationship between length-weight, width-weight and relative condition factor in different months over a period of twenty four months of the study and in different size groups of males and females of $S$. serrata in Coringa mangroves (India).

\section{Materials and Methods}

Crab samples were collected every month from the main landing center Pedavalasala village ( $16^{\circ} 46^{\circ} 45.93^{\prime \prime} \mathrm{N} ; 82^{\circ} 15^{\prime}$ $47.05^{\prime \prime} \mathrm{E}$ ) where all the crab catches in Coringa mangroves were brought and pooled. Sampling was carried out for about twenty four months. The average values of crab samples collected in two months of 2007 and 2008 were used for the study. A total of 693 males and 782 females with more than $20 \mathrm{~mm}$ in size inter moult condition were taken for the study following Kunju (1978). The carapace length $(\mathrm{CL})$ was measured across the carapace between the ninth antero-lateral teeth and carapace width (CW) from tip of anterior margin of the carapace to the anterior margin of first abdominal segment was taken to the nearest $0.1 \mathrm{~cm}$ using a divider and scale. The total weight of the crab was determined using a top pan balance to the nearest point $( \pm 0.1 \mathrm{~g})$. Males and females were grouped into 6 size-classes based on carapace length. They were $2.0-3.9 \mathrm{~cm}, 4.0-5.9 \mathrm{~cm}$, 6.0-7.9 cm, 8.0-9.9 cm, 10.0-11.9 cm and 12.0-13.9 cm. The relationship was derived by the formula of Le Cren (1951):

$\mathrm{W}=\mathrm{cL}^{\mathrm{n}}$,

where $\mathrm{W}=$ weight $(\mathrm{g}), \mathrm{L}=$ length $(\mathrm{cm})$ and ' $\mathrm{c}$ ' and ' $\mathrm{n}$ ' are constants.

The logarithmic expression was $\log \mathrm{W}=\log \mathrm{c}+\mathrm{n} \log \mathrm{L}$, for the determination of the length-weight relationship in crabs as compared to the cube law expressed as

$\mathrm{K}=\mathrm{W} / \mathrm{L}^{3}$, where $\mathrm{K}=$ Growth coefficient, $\mathrm{W}=\mathrm{Weight}$ (g) and $\mathrm{L}=$ Length $(\mathrm{cm})$.

The relationship between carapace length and total weight was exponential. Therefore logarithmic form of the expression $\log _{e} W=\log _{e} a+b \log _{e} L$ was used for determining the relationship between length and weight, where $\mathrm{W}(\mathrm{g})$ is the weight, $\mathrm{L}(\mathrm{mm})$ is the length and 'a' and 'b' are constants representing the intercept and the slope (regression coefficient). The expression $\log _{\mathrm{e}}$ denotes the natural logarithm. The linear equation was converted into the exponential form i.e.

$\mathrm{W}=\mathrm{aL}^{\mathrm{b}}$, where $\mathrm{W}=\mathrm{W}$ eight $(\mathrm{g}), \mathrm{L}=$ Length $(\mathrm{mm}),{ }^{\prime} \mathrm{a}=$ a constant equivalent to ' $c$ ' and ' $b$ ' $=a$ constant to be determined empirically.

The relationship between carapace length-body weights was calculated by the least square method using individual measurements. To determine the significance of the regression coefficients of the relationship in males and females, analysis of covariance (ANCOVA) was used
(Snedecor and Cochran, 1968).

Similarly, the relationship between carapace width and body weight was also studied.

\section{Condition factor $(K)$ and relative Condition factor $(\mathrm{Kn})$}

The condition factor is computed by the formula:

$$
\mathrm{K}=\mathrm{W} \times 10^{5} / \mathrm{L}^{3}
$$

where $\mathrm{K}=$ condition factor, $\mathrm{W}=$ weight $(\mathrm{g})$ and $\mathrm{L}=$ length $(\mathrm{cm})$.

This equation is based on the ideal form where in formula for the length-weight relationship is $\mathrm{w}=\mathrm{aL} \mathrm{L}^{\mathrm{b}}$, where $w$ is the weight, $L$ is the length and 'a' and ' $b$ ' are constants. When $b=3$, the animal will obey the cube law and it will follow the isometric growth pattern (Le Cren, 1951). If it is less than 3 , the animal is exhibiting allometric growth and when $b \geq 3$ the animal is with faster growth. The effect of length on $\mathrm{K}$ however can be eliminated by computing the relative condition factor based on the empirical lengthweight relationship and is calculated by the formula $\mathrm{Kn}=$ $\mathrm{W} / \mathrm{w}^{-}$, where, $\mathrm{Kn}=$ Relative condition factor, $\mathrm{W}=$ observed weight and $\mathrm{w}^{-}=$calculated weight.

The relative condition factor 'Kn' was calculated for each individual crab by dividing the observed weight by calculated weight. The mean ' $\mathrm{K} n$ ' values were estimated in different months during the study period and also against different size classes. The 'Kn' values were estimated separately for both genders. The regression values of carapace length and body weight and carapace width and body weight were estimated.

\section{Results}

\section{Length-weight relationship}

The observed values of carapace length and weight of males, females and combined genders were plotted in Fig.1. The regression values indicated a straight-line relationship between the two variables. The parabolic equations derived for males, females and combined genders were as follows:

Males $\mathrm{W}=0.00000178 \mathrm{~L}^{3.1139}(\mathrm{r}=0.95)$; $\log \mathrm{W}=-$ $0.7324+3.1139 \log \mathrm{L}(\mathrm{r}=0.94)$

Females W $=0.00000520 \mathrm{~L}^{2.8056}(\mathrm{r}=0.94) ; \log \mathrm{W}=-$ $0.5177+2.8056 \log \mathrm{L}(\mathrm{r}=0.94)$

Genders combined $\mathrm{W}=0.0000297 \mathrm{~L}^{2.9891}(\mathrm{r}=0.94)$; $\log W=-0.6517+2.9891 \log L(r=0.97)$.

Analysis of covariance (F-test) revealed significant difference at 5\% level in males, females and genders combined (Table 1). The exponent ' $\mathrm{b}$ ' value in males was 3.1139 , so the pattern of growth was positive allometry. In case of females it was 2.8056 indicating that the growth was of negative allometry. Moreover, the crabs were sexually dimorphic i.e., males were larger to females. It was supported by the ' $\mathrm{b}$ ' value. When the genders combined were studied, it was 2.9891, indicating almost all isometric growth.

\section{Width-weight relationship}

The regression values showed a straight-line relationship between the width and weight (Fig. 2). The parabolic equations derived for males, females and genders combined were as follows: 
Table 1. Comparison of regression lines of length-weight relationship in males, females and genders combined of S. serrata

\begin{tabular}{|c|c|c|c|c|c|c|c|c|}
\hline \multirow{2}{*}{ Gender } & \multicolumn{4}{|c|}{ Corrected sum of squares and products } & \multirow{2}{*}{$\begin{array}{l}\text { Regression co- } \\
\text { efficient (b) }\end{array}$} & \multicolumn{3}{|c|}{ Deviations from regression } \\
\hline & d.f & $\sum \mathrm{X}^{2}$ & $\sum X Y$ & $\sum \mathrm{Y}^{2}$ & & d.f & S.S & M.S.S \\
\hline Males & 692 & 14.6884 & 6.8749 & 151.4243 & 3.1139 & 691 & 8.9993 & 0.01302 \\
\hline Females & 781 & 13.219 & 4.6003 & 110.5129 & 2.8056 & 780 & 6.4606 & 0.00825 \\
\hline Pooled (within) & & & & & & 1,471 & 15.4598 & 0.01051 \\
\hline Combined & 1,473 & 27.9375 & 11.4752 & 261.9372 & 2.9891 & 1,472 & 16.5596 & 0.01125 \\
\hline Slopes & & & & & & 1 & 1.0998 & 1.0998 \\
\hline
\end{tabular}

Slopes, $\mathrm{F}=104.64$ (d.f 1.1471) significant at $5 \%$ level; d.f = Degrees of freedom; $\Sigma \mathrm{X}^{2}, \Sigma X Y, \Sigma \mathrm{Y}^{2}=$ corrected sum of squares and products; S.S = Sum of Squares; M.S.S = Mean Sum of Squares
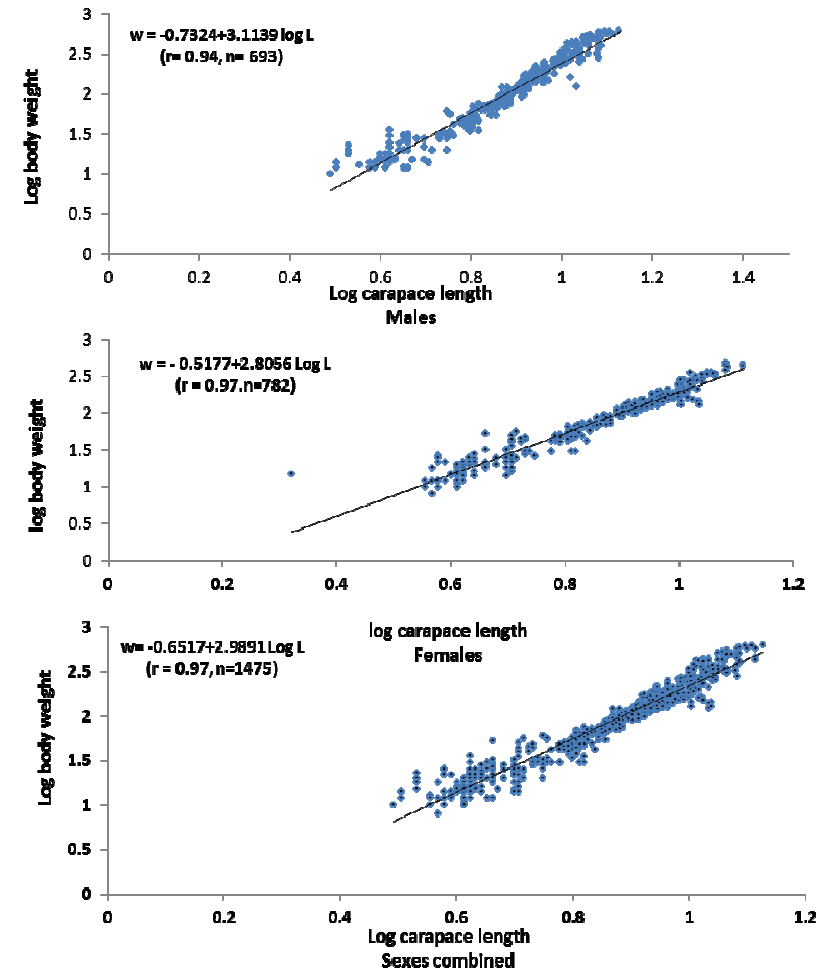

Fig. 1. Scatter diagram showing logarithmic relationship of carapace length-weight relationship of $S$. serrata in males, females and genders combined

Males $\mathrm{W}=0.00000121 \mathrm{CW}^{3.0426}(\mathrm{r}=0.92) ; \log \mathrm{W}=$ $-0.1661+3.0426 \log \mathrm{CW}(\mathrm{r}=0.93)$

Females W=0.00000178 CW $\mathrm{CW}^{2.775}(\mathrm{r}=0.93) ; \log \mathrm{W}=$ $-0.0466+2.775 \log \mathrm{CW}(\mathrm{r}=0.92)$

Genders combined W=0.00000204 CW ${ }^{2.9210}(\mathrm{r}=$ $0.92) ; \log \mathrm{W}=-0.1169+2.9210 \log \mathrm{CW}(\mathrm{r}=0.92)$.

Analysis of covariance (F-test) revealed significant difference at 5\% level in males, females and genders combined (Table 2). The exponent 'b' value was more in males i.e., 3.0426 so the pattern of growth was positive allometry. In case of females it was 2.775 indicating negative allometry.
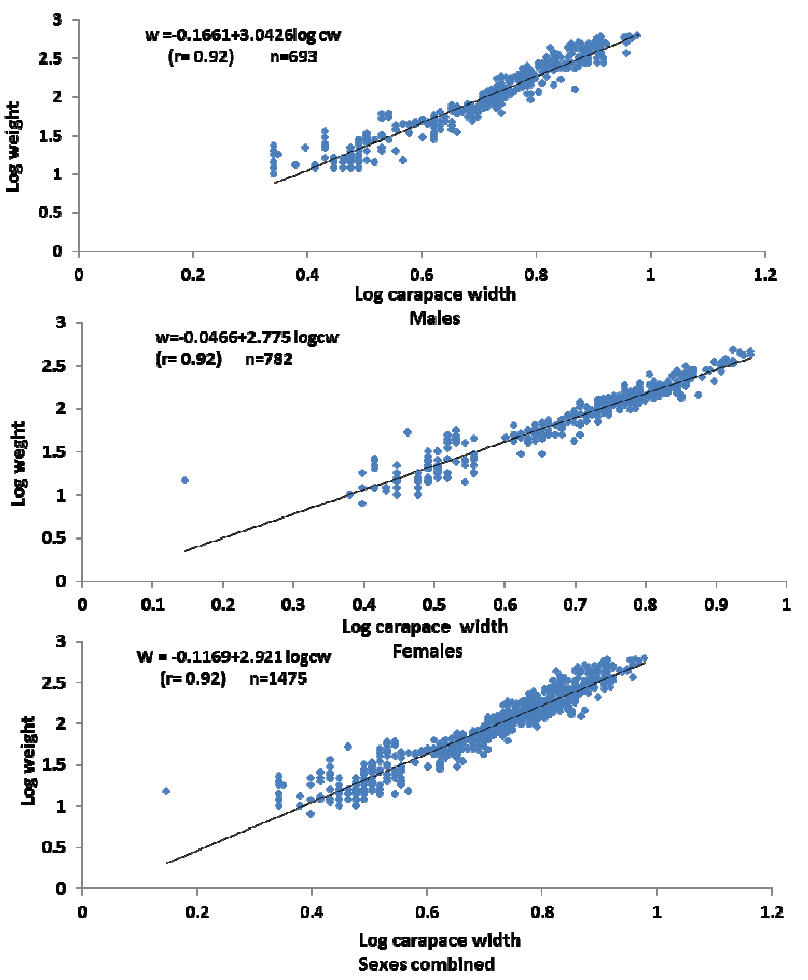

Fig. 2. Scatter diagram showing logarithmic relationship of carapace width-weight relationship of $S$. serrata in males, females and genders combined

\section{Relative condition factor (Kn)}

The mean $\mathrm{Kn}$ values were estimated for males, females and genders combined separately every month and also in different size groups.

\section{Month-wise mean Kn values}

Males showed a low value of 0.760 in April and a high value of 1.046 in November followed by December with 1.01. In case of females, the values ranged from 0.755 in April to 1.015 in November. When the values of genders combined were studied, the highest value was recorded in November (1.037) and the lowest in April (0.764) (Fig. 3).

Table 2. Comparison of regression lines of width-weight relationship in males, females and genders combined of $S$. serrata

\begin{tabular}{|c|c|c|c|c|c|c|c|c|}
\hline \multirow{2}{*}{ Gender } & \multicolumn{4}{|c|}{ Corrected sum of squares and products } & \multirow{2}{*}{$\begin{array}{c}\text { Regression co- } \\
\text { efficient (b) }\end{array}$} & \multicolumn{3}{|c|}{ Deviations from regression } \\
\hline & d.f & $\sum \mathrm{X}^{2}$ & $\sum X Y$ & $\sum \mathrm{Y}^{2}$ & & d.f & S.S & M.S.S \\
\hline Males & 692 & 15.1014 & 6.91242 & 151.4237 & 3.0426 & 691 & 11.6238 & 0.01682 \\
\hline Females & 781 & 13.3447 & 4.52935 & 110.521 & 2.775 & 780 & 7.75848 & 0.00995 \\
\hline Pooled (within) & & & & & & 1471 & 19.3823 & 0.01317 \\
\hline Combined & 1473 & 28.4527 & 11.4649 & 264.5257 & 2.921 & 1472 & 21.75998 & 0.01478 \\
\hline Slopes & & & & & & 1 & 2.3777 & 2.37771 \\
\hline
\end{tabular}

Slopes, $F=180.54$ (d.f 1.1471) significant at $5 \%$ level; d.f = Degrees of freedom; $\sum \mathrm{X}^{2}, \sum X Y, \sum \mathrm{Y}^{2}=$ corrected sum of squares and products; S.S= Sum of Squares; M.S.S=

Mean Sum of Squares 
Size-group wise mean Kn values

The average Kn values gradually increased with the increasing size of the crabs. In males, the highest value of $\mathrm{Kn}$ was observed in 12.0-13.9 $\mathrm{cm}$ size class with 1.248 and the lowest value of 0.595 was in $4.0-5.9 \mathrm{~cm}$ size group. A gradual increase was noticed from 4.0-5.9 $\mathrm{cm}$ size class to 12.0-13.9 $\mathrm{cm}$. In females, the peak value (1.378) was noticed in the size group of $12.0-13.9 \mathrm{~cm}$ and a low value (0.703) in 4.0$5.9 \mathrm{~cm}$ size group. Regarding the genders combined, a peak value was found at $12.0-13.9 \mathrm{~cm}$ and the lowest value in 4.0$5.9 \mathrm{~cm}$ size group (Fig. 4).

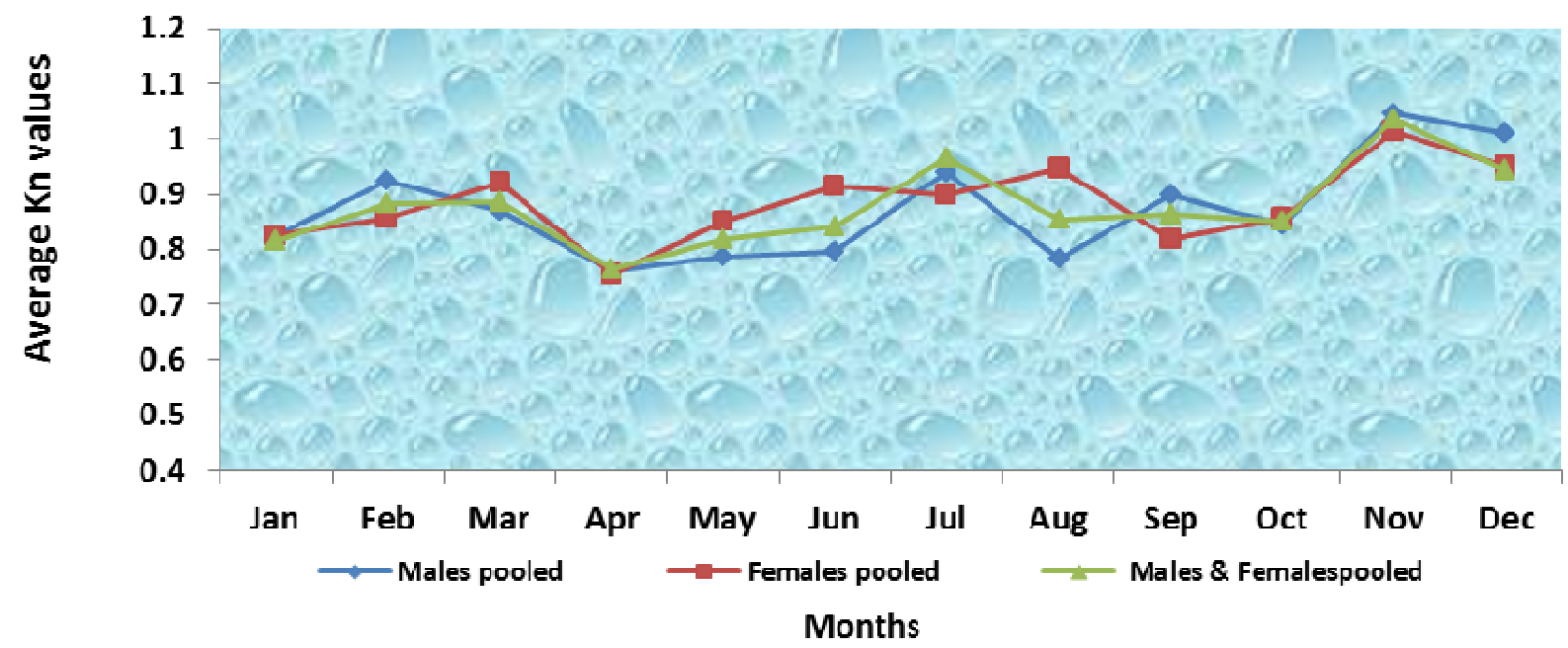

Fig. 3. Month-wise condition factor of $S$. serrata in males, females and genders combined

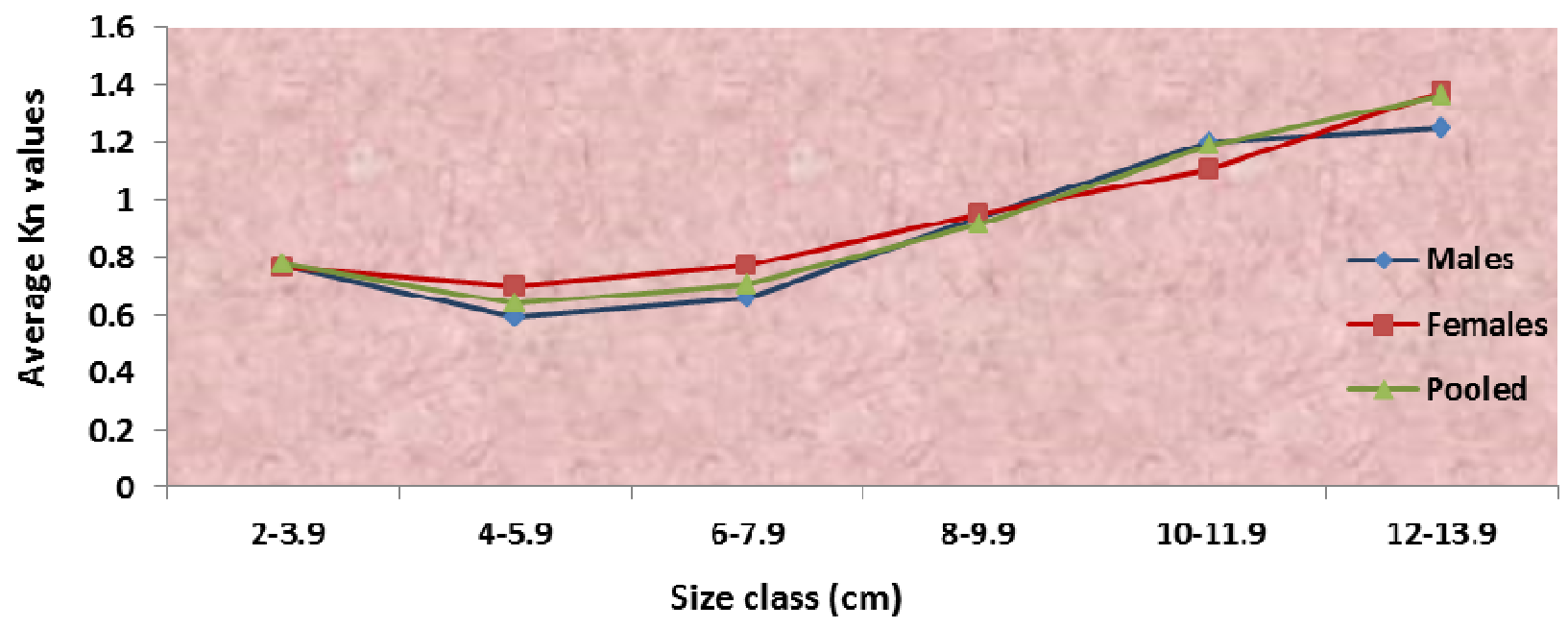

Fig. 4. Length-wise condition factor of $S$. serrata in males, females and genders combined

\section{Discussion}

The overall size of crab $S$. serrata recorded in the present study ranged from $3.1 \mathrm{~cm}$ to $13.4 \mathrm{~cm}$ with a mean carapace length of $7.99 \mathrm{~cm}$ in males, and 3.6 to $13.0 \mathrm{~cm}$ with an average of $7.74 \mathrm{~cm}$ in females. The mean weight of male crab was $165 \mathrm{~g}$ and that of female was $114 \mathrm{~g}$. An overall study brings to light that the females have shown less weight to males of the same size class. The model size class observed in the two years was $8.0-9.9 \mathrm{~cm}$ carapace length in both males and females. Lalitha Devi (1985) has reported size ranging from $15 \mathrm{~mm}$ to $129 \mathrm{~mm}$ in $S$. serrata in the backwaters of Kakinada. Mohapatra et al. (2006) have reported the similar carapace width in $S$. serrata, from $20-181 \mathrm{~cm}$, in Chilika lagoon. A little bigger size of $46-215 \mathrm{~mm}$ was reported in $S$. serrata from Korapuzha estuary in Kerala (Sarada, 1997).
A gradual decrease in the size of the crab i.e., from 7.87 $\mathrm{cm}$ to $7.84 \mathrm{~cm}$ in carapace length and in weight from 142.34 $\mathrm{g}$ to $133 \mathrm{~g}$ has been noticed in the present study. It may be due to the environmental impact or over-exploitation of small sized crabs. The average size of $S$. serrata recorded in West Bengal coast was $90.05 \mathrm{~mm}$ carapace width and 62 $\mathrm{mm}$ carapace length by Bandyopadhyay (2008). Nandi and Pramanik (1994) had observed $180 \mathrm{~mm}$ carapace width and $140 \mathrm{~mm}$ carapace length. In Andaman Islands the average carapace width recorded was $112 \mathrm{~mm}$ and the carapace length was $80 \mathrm{~mm}$ (Poovichiranon, 1992). Mohapatra et al. (2006) had noticed that the carapace width varyied between $21 \mathrm{~mm}$ to $150 \mathrm{~mm}$ and body weight between $5 \mathrm{~g}$ to $720 \mathrm{gm}$ in Sundarbans. The largest size of male and female S. serrata reported by Mohapatra (2006) from Chilka lagoon of Orissa, India, was $181 \mathrm{~mm} / 0.83 \mathrm{~kg}$ and 
342

$159 \mathrm{~mm} / 0.68 \mathrm{~kg}$ respectively. The carapace length ranging from 50 to $125 \mathrm{~mm}$ with a peak at $75 \mathrm{~mm}$ for male and 70 $\mathrm{mm}$ for female crabs have been observed by Fondo et al. (2010) in S. serrata. According to them, the female crabs are smaller in size than the male crabs. The difference mean carapace length for male and female i.e., $85 \mathrm{~mm}$ and $81 \mathrm{~mm}$ observed by them is not statistically significant. A positive allometric growth for males and negative for females have been observed by Fondo et al. (2010). Similar growth pattern has been recorded in the present study also with exponent ' $b$ ' value 3.1139 for males and 2.8056 for females, indicating the positive and negative allometric growth pattern respectively.

The length frequency distribution population has shown a unimodal size distribution and majority of the crabs caught were of small and medium size class only. The logarithmic relation between weight and carapace length and also between weight and carapace width indicated a linear relationship signifying the increase in weight with increase in length or width. The calculated ' $b$ ' values have shown a clear sexual dimorphism between males and females with larger males than females of the same group. This is in correlation with the findings of Poovachiranon (1992) in Andaman Sea, Khan and Alam (1992) in Bangladesh and Zafar et al. (2006) in Southern coastal region of Bangladesh, Fond et al. (2010) in Kenya, Mahopatra et al. (2010) in Chilka lake etc., where higher 'b' values for male crabs than female crabs of $S$. serrata were observed. Warner (1997) opined that in true crabs, the males are generally larger than females. There is positive correlation between carapace length and total weight, and carapace width and total weight of the crabs of the study area. Mohapatra et al. (2010) has also observed a positive correlation between the length and weight in both the species of Scylla in Chilka lagoon of Orissa. Thirunavukkarasu and Shanmugam (2011) observed the 'b' values of length-weight and width-weight relationships to be 3.1408 and 2.8291 and 3.2718 and 3.0202 for male and female crabs respectively in $S$. tranquebarica.

The value of relative condition factor ranged from 0.65 to 1.37 in the overall study period and it has shown a significant difference with crab size and month of investigation. However, crabs of bigger size showed higher value. The relative condition factor in the present study was higher in males than the females. This is in correlation with the findings of Mohapatra et al. (2010) in S. serrata of Chilika lagoon. The relative condition factor of males was recorded a peak in November and there after decreased slowly in April and May. The females have shown the peak $\mathrm{kn}$ value in the month of November followed by December. Higher Kn value in the month of November reflects the peak breeding season of $S$. serrata in Coringa mangroves in the winter season i.e., in the last quarter of the year (October to December) and the juveniles are more abundant in the first half of the year. Pillai et al. (2002) reported that the growth rate has been decreased during April-May due to the increased salinity. This may be the reason for the low relative condition factor in the months of April and May in the study area. Afterwards, a gradual increase in growth and reaching peak in winter months has been observed. Fluctuations in the relative condition factor at different size groups in both genders has been noticed in mud crab $S$. serrata by Ali et al. (2004) and according to them the Kn values ranged from 0.41 to 1.53 and 1.037417 to 1.00746 in male and female respectively. Generally seasonal variation of relative condition factor is more or less related to the sexual cycle of the species (Le Cren, 1951).

As far as the sized-based relative condition factor, it has been found to be high in larger size groups. The $\mathrm{Kn}$ values are low in the size group of $4.0-5.9 \mathrm{~cm}$ size class in both male and female, in both years. Similar observation has been made in S. serrata and S. tranquebarica of Chilika lagoon by Mohapatra et al. (2010). Oluwatoyin et al. (2013) have found the condition factor $\mathrm{k}$ for male (66.52), female (67.64) and for the entire population 66.89 in Callinectes pallidus and also found a significant difference $(\mathrm{P}>0.01)$ in condition factor between the genders. Laura et al. (2016) have found the average values of condition factor for mangrove crabs identical in the coastal waters of Indonesia.

\section{Conclusions}

The male crabs showed positive allometric growth, whereas females had negative allometric growth. Analysis of covariance confirmed remarkable difference between males and females in the growth pattern. The mean relative condition factor (Kn values) of both males and females and of the pooled genders ranged from 0.680 (April) to 1.029 (November). A gradual raise in $\mathrm{Kn}$ values was observed from small- to big- sized crabs in both genders. Peak values were observed in $12.0-13.9 \mathrm{~cm}$ size group, in November.

\section{Acknowledgements}

The authors are grateful to the Head Department of Marine Living Resources, Andhra University, Visakhapatnam (India) for providing facilities to carry out research work.

\section{References}

Abdur Rouf MD, Sheik Istiak MD, Shahriar MD, Golam S, Nazmul A $\mathrm{MD}$ (2016). Taxonomic clarification of mud crab species of genus Scylla (Brachyura: Portunidae) available in the Coastal Regions of Bangladesh. Asian Fisheries Science 29:124136.

Ali MY, Kamal D, Hossain SMM, Azam W, Sabbir A, Murshida Ahmed B, Azam K (2004). Biological studies of mud crab, Scylla serrata (Forskal) of the Sundarbans Mangrove Ecosystem in Khulna Region of Bangladesh. Pakistan Journal of Biological Sciences 7(11):1981-1987.

Atar HH, Secer S (2003). Width/length-weight relationships of the blue crab (Callinces sapidus Rathbun 1896) population living in Beymelek Lagoon Lake. Turkish Journal of Veterinary and Animal Sciences 27:443-447.

Bonine KM, Bjorkstedt EP, Ewel KC, Palik M (2008). Population Characteristics of the Mangrove Crab Scylla serrata (Decapoda: Portunidae) in Kosrae, Federated States of Micronesia: Effects of Harvest and Implications for Management Pacific Science 62(1):1-19.

Bandyopadhyay P (2008). Crabs of Coastal Waters of West Bengal. Their occurrence and seasonal abundance. Fishing Chimes 28(4):11-13. 
Dai A, Yang S (1991). Crabs of the China seas. China Ocean Press. Beijing, China, 682pp.

Davis AJ (2004). Spawning Characteristics of the South African Mud crab Scylla serrata (Forskal) in Captivity. Journal of the World Aquaculture Society 35(2):121-133.

Ewel KC (2008). Mangrove crab (Scylla serrata) populations may sometimes be best managed locally.Journal of Sea Research 59:114-120.

Fondo EN, Edward N, Kimani DO, Odongo O (2010). The status of mangrove mud crab fishery in Kenya, East Africa. International Journal of Fisheries and Aquaculture 2(3):79-86.

Hill BJ (1975). Abundance, breeding and growth of the Crab Scylla serrata in two South African estuaries. Marine Biology 32:119-126.

Khan G, Alam F (1992). The bio-economics and fishery of mud crab Scylla serrata in Bangladesh. Paper presented at the International Seminar on Mud Crab Culture and Trade in the Bay of Bengal Region. 5-8 November, 1991, Surat Thani, Thailand 1-37 pp.

Kunju MM (1978). Growth in prawns. Central Marine Fisheries Research Institute Special Publication 3:48-57.

Lalitha Devi S (1985). The fishery and biology of crabs of Kakinada region. Indian Journal of Fisheries 32(1):18-32.

Laura S, Natan Y, Khouw AS, Pattikawa JA (2016). Size distribution, growth pattern and condition factor of mangrove crab Scylla serrata in the coastal waters of Western Seram, Maluku, Indonesia. International Journal of Fisheries and Aquatic Studies 4(2):291-296.

Le Cren ED (1951). The length-weight relationships and seasonal cycle in gonad weight and condition in the Perch (Perca flaviatilis). Journal of Animal Ecology 20(2):201-219.

Mohapatra A (2008). Fishery, biology and ecology of mud crabs (Scylla sp.) from Chilika lagoon-A coastal wetland ecosystem. PhD Thesis, F.M. University, Balasore(Orissa).

Mohapatra A, Mohanty RK, Mohanty SK, Bhatta KS, Pattanaik AK (2006). Occurrence and biological outlines of two species of Scylla in Chilkalagoon, India Indian Journal of Fisheries 53:191-202.

Mohapatra A, Mohanty RK, MohantySK, DeySK (2010). Carapace width and weight relationships, condition factor, relative condition factor and gonado-somatic index (GSI) of mud crabs (Scylla spp.) from Chilika Lagoon, India. Indian Journal of MarineSciences 39(1):120-127.

Nandi NC, Dev Roy MK (1996). Burrowing activity and distribution of Scylla serrata (Forskal) from Hooghly and Matla estuaries, Sundarbans, West Bengal. Journal of Bombay Natural Historical Society 88:167171.

Nandi NC, Pramanik SK (1994). Crab and crab fisheries of Sundarbans. Hindustan PublishingCorporation, Delhi.
Oluwatoyin A, Adeboyejo A, Clarke E, Kusemiju V (2013). A study of length-weight relationship and condition factor of west African blue crab (Callinectes pallidus) from Ojo Creek, Lagos, Nigeria. American Journal of Research Communication 1(3):102-114.

Overton JL, Macintosh DJ, Thrope RS (1997). Multivariate analysis of the mud crab Scylla serrata (Brachyura: Portunidae) from four location in South East Asia. Marine Biology 128:55-62.

Pillai SL, Rajapackiam S, Sunderarajan D (2002). Mud crab Scylla tranquebarica culture in earthen pond at Tuticorin. Journal of Marine Biological Association of India 44(182):245-248.

Prasad PN, Neelakantan B, Kusuma MS (1990). Distribution and abundance of the mud crab Scylla serrata from Karwar waters. Environmental Ecology 8:798-804.

Poovichiranon S (1992). Biological studies of the mud crab Scylla serrata of mangrove ecosystem in the Andaman Sea. In: Angell CA (Ed). Report of the seminar on mud crab culture and trade. Bay of Bengal Programme. Madras, Bay of Bengal Programme/Report/51:49-59.

Rattanachote A, Dangwatanakul R (1992). In: Angell CA (Ed). Report of seminar on the mud crab culture and trade held at Surat Thani, Thailand. Bay of Bengal Programme. Madras, Bay of Bengal Programme/Report/51.Madras, Indiapp 171-177.

Sarada PT (1997). Exploitation of mud crab Scylla serrata (Forskal) from Korapuzha estuary, Kerala. Journal of Marine Biological Association of India39(1\&2):113-117.

Sakai T (1976). Crabs of Japan and the adjacent seas. Kodansha, Tokyo pp 335-336.

Sukumaran KK, Neelakantan B (1997). Length-weight relationship in two marine portunid crabs, Portunus sanguinolentus and $P$. pelagicus from the Karnataka coast. Indian Journal of Marine Science 26:39-42.

Snedecor GW, Cochran WG (1968). Statistical Methods. Oxford and IBH PublishingCo, Calcutta.

Thirunavukkarasu N, Shanmugam A (2011). Length-weight and widthweight relationships of mud crab Scylla tranquebarica (Fabricius, 1798). Journal of Marine Biological Association of India 53(1):142-144.

Waiho K, Fazhan H, Ikhwanuddin M (2016). Size distribution, lengthweight relationship and size at the onset of sexual maturity of the orange mud crab, Scylla olivacea, in Malaysian waters. Marine Biology Research 12:726-738.

Warner GF (1997). The biology of crab. Paul Elek (Scientific book). Ltd. London.

Zafar M, Nurul Amin SM, Rahman MM (2006). Population dynamics of mud crab (S. serrata) in the southern coastal region of Bangladesh. Asian Fisheries Science 19:43-50. 